\title{
ESTUDO DA ESTABILIDADE FÍSICO-QUÍMICA E MICROSCOPICA DE IOGURTE NATURAL LIOFILIZADO DURANTE O ARMAZENAMENTO
}

\author{
C.M.S.MATOS ${ }^{*}{ }^{*}$, M.S.DE JESUS ${ }^{1}$, G.S.SILVA ${ }^{1}$, T.P.NUNES ${ }^{2}$, A.A.C.PAGANI ${ }^{2}$ \\ ${ }^{1}$ Universidade Federal de Sergipe, Departamento de Tecnologia de Alimentos \\ ${ }^{2}$ Universidade Federal de Sergipe, Departamento de Tecnologia de Alimentos \\ *e-mail: c.moraismatos@gmail.com
}

\begin{abstract}
RESUMO
O iogurte é mundialmente conhecido e apreciado pelos consumidores por ser um produto de alto valor sensorial e por ser uma alternativa de utilização do leite. Visando essa importância no mercado alimentício mundial há sempre uma procura de diversificar este produto, e aumentar sua disponibilidade e duração. Assim o presente trabalho tem como objetivo estudar o processo de liofilização na conservação por 2 meses das características físico-químicas do iogurte natural. Os ingredientes para a formulação do Iogurte Natural tais como leite UHT integral e iogurte natural para ser o inóculo das bactérias necessárias foram adquiridos em supermercados locais. O leite foi homogeneizado com $40 \mathrm{~g}$ de leite em pó e $60 \mathrm{~g}$ de açúcar, foi transferido para um recipiente de inox e aquecido a $95^{\circ} \mathrm{C}$ por 5 minutos para pasteurização dos ingredientes. A seguir, o leite foi resfriado até $43^{\circ} \mathrm{C}$ para adição do inóculo (iogurte natural industrial). Após a adição do inóculo o leite foi transferido de forma asséptica para um recipiente estéril, sendo encaminhado posteriormente a BOD á temperatura de $43^{\circ} \mathrm{C}$ por aproximadamente 5 horas, em seguida o iogurte foi resfriado gradativamente até atingir a temperatura de $6^{\circ} \mathrm{C}$, atingido essa temperatura o iogurte foi levado ao refrigerador $5^{\circ} \mathrm{C}$ por $24 \mathrm{~h}$. Todas as análises físico-químicas foram realizadas em triplicata, a fim de caracterizar os produtos e notificar as diferenças entre os mesmos e de acordo com as Normas do Instituto Adolfo Lutz (2005). Os resultados obtidos do iogurte liofilizado após 2 meses não mostraram grandes diferenças se comparado ao mesmo iogurte antes de ser liofilizado, isso mostra que o processo de liofilização é eficaz quando se trata da conservação das características físico-químicas do iogurte, aumentando sua vida de prateleira que geralmente é de um mês, para dois meses.
\end{abstract}

\section{INTRODUÇÃO}

A origem do iogurte deve situar-se no Oriente Médio ou na Índia. Os pastores nômades, ao armazenar o leite sempre nos mesmos recipientes, foram selecionando uma microbiota que fermentava o leite e produzia um alimento de sabor agradável. Além disso, o alto grau de acidez conseguido não permitiria o desenvolvimento de bactérias patogênicas (ORDÓÑEZ, 2005).

Produzido através de leite fermentado por bactérias, usualmente Lactobacillus bulgaricus e Streptococcus thermophilus, o iogurte possui uma consistência que o diferencia de outros produtos derivados de 
lacticínios. Contém todos os constituintes nutricionais do leite, com exceção da lactose, reduzida durante a fermentação, revelando-se vantajoso para quem não digere bem o leite (DA SILVA, 2010). No início da fermentação, o $\mathrm{pH}$ do leite favorece o desenvolvimento do Streptococcus thermophilus. Com o aumento da acidificação, ou seja, do teor de ácido láctico produzido a partir da lactose, crescem os Lactobacillus bulgaricus (HANSEN, 2002; RODAS, 2001; MAZZA, 1998).

\subsection{Leite}

Entende-se por leite, sem outra especificação, o produto oriundo da ordenha completa, ininterrupta, em condições de higiene, de vacas sadias, bem alimentadas e descansadas. O leite de outras espécies deve denominar-se segundo a espécie da qual proceda (SENAR, 2010). Devido aos aspectos sensoriais, nutricionais e especialmente os funcionais do leite, seu consumo vem crescendo vertiginosamente ao longo dos últimos anos, apesar disso o consumo per capita no Brasil ainda é pequeno já que muitas pessoas o vêm apenas como uma sobremesa (TAMINE e DEETH, 1980).

\subsubsection{Liofilização}

A liofilização é uma técnica de secagem que retira a umidade contida no material através do congelamento da parte líquida e posterior sublimação do gelo, passagem da água do estado sólido para o gasoso. Por trabalhar com baixas temperaturas e, geralmente sob vácuo, esse processo é recomendado para materiais termosensíveis, materiais biológicos (fungos, enzimas, tecidos, sangue, cobaias), farmacêuticos (antibióticos, vacinas, sorros), alimentos (sucos, carnes, legumes, frutas) e produtos químicos; gerando produtos de qualidade supeior quando comparado às outras técnicas de secagem (PITOMBO, 1989; LOMBRAÑA \& IZKARA, 1996; RATTI, 2001).

\section{MATERIAL E MÉTODOS}

\subsection{Obtenção do leite e produção do iogurte natural}

Os ingredientes para a formulação do Iogurte Natural tais como leite UHT integral e iogurte natural foram adquiridos em supermercados locais e transportados em condições assépticas até o Laboratório de Processamento de Origem Animal (LPOA) localizado na Universidade Federal de Sergipe para a elaboração do iogurte.

$\mathrm{O}$ iogurte natural foi processado utilizando-se $1 \mathrm{~L}$ de leite integral tipo UHT. O leite foi transferido para um liquidificador onde foi misturado com $40 \mathrm{~g}$ de leite em pó e $60 \mathrm{~g}$ de açúcar, após a homogeneização foi transferido para um recipiente de inox e aquecido a $95^{\circ} \mathrm{C}$ por 5 minutos para pasteurização dos ingredientes. A seguir, o leite foi resfriado até $43^{\circ} \mathrm{C}$ para adição do inóculo (iogurte natural industrial).

Após a adição do inóculo o leite foi transferido de forma asséptica para um recipiente estéril, sendo encaminhado posteriormente a BOD á temperatura de $43^{\circ} \mathrm{C}$ por aproximadamente 5 horas onde o leite fermentado atingiu valores de $\mathrm{pH}$ entre 4,5 e 4,6 , em seguida o iogurte foi resfriado gradativamente até atingir a temperatura de $6^{\circ} \mathrm{C}$, atingido essa temperatura o iogurte foi levado ao refrigerador $5^{\circ} \mathrm{C}$ por $24 \mathrm{~h}$, para diminuir o processo fermentativo e adquirir sabor, odor e textura característicos.

\subsection{Processamento do iogurte liofilizado}

Após o processamento do iogurte as amostras foram depositadas em bandejas de aço inoxidável do liofilizador (Christ modelo Alpha 1-2 LSC), posteriormente foram congeladas em freezer (Electrolux Modelo FE 26) a temperaturas de $-25 \pm 2^{\circ} \mathrm{C}$ por 24 horas, em seguida foram inseridas no liofilizador com uma temperatura de $-37{ }^{\circ} \mathrm{C}$ na sua câmara de condensação e em vácuo a uma pressão mínima de 0,18 mbar por 48 horas. 
Depois de desidratadas foi realizada a microscopia com o uso de um microscópio digital da Marca Dino Lite. Esta análise foi realizada logo após a liofilização e depois de trituradas, com a finalidade de se obter um produto na forma de pó. As amostras foram trituradas em liquidificador por cerca de 30 segundos e peneiradas para obtenção de um produto homogêneo, as amostras foram armazenadas em embalagens laminadas (polipropileno e alumínio), sendo posteriormente selada a vácuo em seladora (TEC MAQ, Modelo AP 500). Todo processo foi realizado em condições assépticas.

\subsection{Análises Físico-químicas}

Todas as análises foram realizadas em triplicata, a fim de caracterizar os produtos e notificar as diferenças entre os mesmos e de acordo com as Normas do Instituto Adolfo Lutz (2005), compreendendo umidade, extrato seco total, atividade de água, cinzas ou resíduo mineral fixo, determinação de acidez, teor de lipídeos, sólidos solúveis ( ${ }^{\circ}$ brix), $\mathrm{pH}$. A microscopia foi realizada com um microscópio digital da Marca Dino Lite a 230x.

\section{RESULTADOS E DISCUSSÃO}

Após a secagem, o iogurte foi pesado e este valor foi comparado com o peso referente à quantidade de massa do iogurte tradicional utilizado para produção do iogurte seco. Após sofrer o processo de secagem: $1045 \mathrm{~g}$ de iogurte natural resulta em $174 \mathrm{~g}$ de iogurte seco. Para encontrar a porcentagem de rendimento, tem-se a equação 1 , que expressa a relação do peso do iogurte tradicional e o peso do iogurte seco.

$\%$ Rendimento $=\frac{P i}{P f} \times 100$

Assim sendo, tem-se um rendimento de $16,7 \%$ após o processo de liofilização. Foi também realizado a microscopia do iogurte após o processo de liofilização. Percebe-se pela Figura 1 que o iogurte após a liofilização apresenta-se em forma de flocos, necessitando assim de uma trituração para ter característica de pó como mostra a figura 2 .

Figura 1 - Microscopia do iogurte liofilizado em forma de flocos

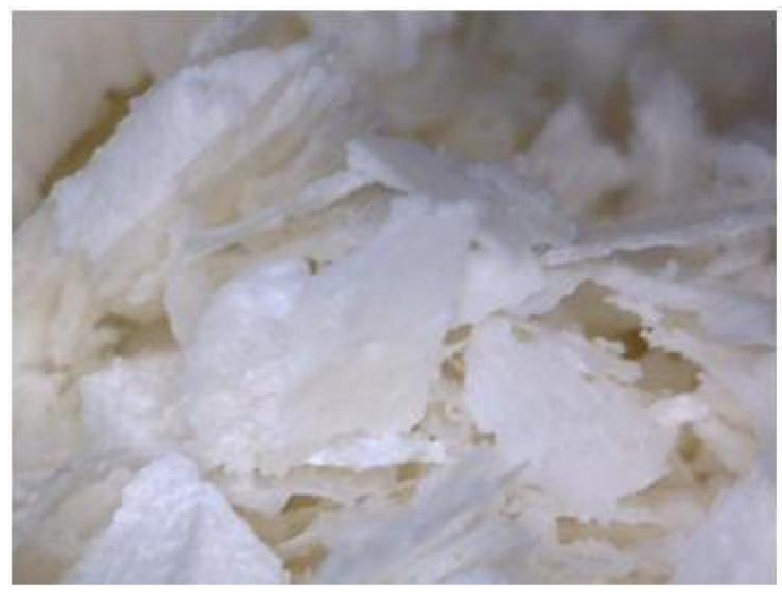

Fonte: Autor (2015).

Figura 2 - Microscopia do iogurte liofilizado em pó

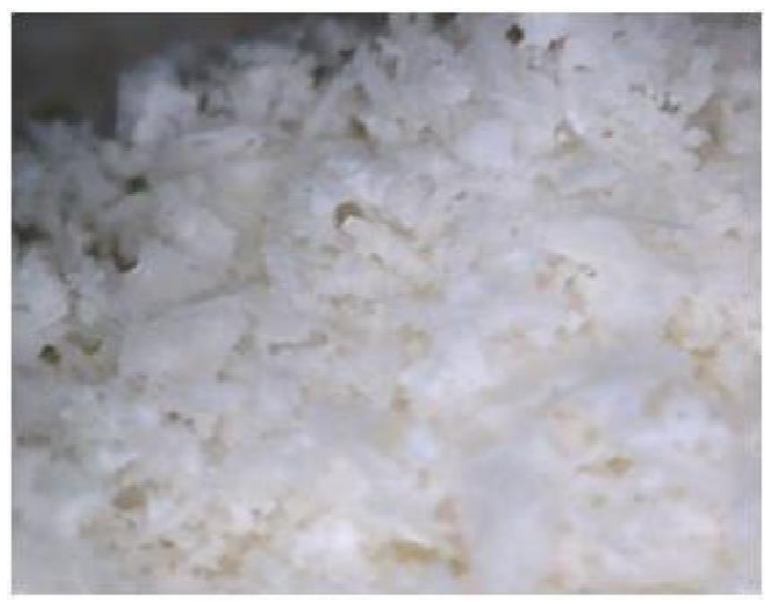

Fonte: Autor (2015).

A Tabela 1 apresenta os resultados das análises físico-químicas do iogurte in natura e do iogurte após liofilização. 
Tabela 1 - Análises físico-químicas realizadas em iogurte in natura e iogurte liofilizado.

\begin{tabular}{ccc}
\hline $\begin{array}{c}\text { Parâmetros } \\
\text { Analisados }\end{array}$ & $\begin{array}{c}\text { Iogurte } \text { in } \\
\text { natura }\end{array}$ & $\begin{array}{c}\text { Iogurte } \\
\text { liofilizado }\end{array}$ \\
\hline $\begin{array}{c}\text { Umidade } \\
(\%)\end{array}$ & $78,50 \pm 0,16$ & $5,56 \pm 0,25$ \\
$\begin{array}{c}\text { Extrato seco } \\
\text { total }\end{array}$ & $16,40 \pm 0,32$ & $28,6 \pm 0,36$ \\
$\begin{array}{c}\text { Atividade de } \\
\text { água }\end{array}$ & $0,9833 \pm 0,0004$ & $0,292 \pm 0,0003$ \\
$\begin{array}{c}\text { Cinzas }(\%) \\
\text { Acidez em }\end{array}$ & $0,94 \pm 0,01$ & $7,21 \pm 0,01$ \\
ácido lático \\
$\quad \%)$
\end{tabular}

Todos os resultados das análises físico-químicas estavam dentro dos parâmetros mínimos definidos pela legislação brasileira para o produto in natura ser considerado iogurte.

Após 2 meses essas análises foram repetidas no iogurte liofilizado reconstituído com 100mL de água destilada até obter a mesma textura do iogurte in natura, para avaliar o processo de armazenamento do mesmo. A Tabela 2 mostra os valores obtidos
Tabela 2 - Análises físico-químicas realizadas em iogurte liofilizado reconstituído.

\begin{tabular}{c|c}
\hline Parâmetros Analisados & $\begin{array}{c}\text { Iogurte liofilizado } \\
\text { reconstituído }\end{array}$ \\
\hline Umidade (\%) & $74,9 \pm 0,18$ \\
Extrato seco total & $15,4 \pm 0,33$ \\
Atividade de água & $0,9824 \pm 0,0004$ \\
Cinzas (\%) & $0,91 \pm 0,02$ \\
Acidez em ácido lático & $0,92 \pm 0,02$ \\
(\%) & $3,64 \pm 0,01$ \\
Teor de lipídeos $(\%)$ & $21,03 \pm 0,03$ \\
Sólidos solúveis \\
$\left({ }^{\circ}\right.$ Brix $)$ \\
pH
\end{tabular}

Fonte: Autor (2015)

Ao observar os valores obtidos após dois meses de estocagem do produto liofilizado, é possível ver uma variação nos resultados, mas que ainda deixa o iogurte reconstituído dentro dos parâmetros mínimos definidos pela legislação brasileira, mostrando que a liofilização é um excelente processo para conservação das características físicoquímicas do iogurte.

\section{CONCLUSÃO}

Face aos resultados obtidos no presente trabalho, pode-se afirmar que no tempo de 2 meses, a liofilização é um processo de secagem apto para conservação das características físico-químicos do iogurte, afim de aumentar sua vida de prateleira. Esse trabalho ainda está em andamento, ou seja, o produto está armazenado por mais um período de 6 meses, com a finalidade de colocar em prova a capacidade de conservação do 
processo de liofilização em iogurte natural por um maior tempo.

\section{NOMENCLATURA}

$\mathrm{Pi}=$ Peso do iogurte seco em gramas

$\mathrm{Pf}=$ Peso do iogurte tradicional em gramas

\section{REFERÊNCIAS}

DA SILVA, Ana Inês Dias; PEREIRA, Flávio José da Costa; BEIRÃO, Marcelo Cardoso da Rocha Vilhena; GOMES, Mariana Rodrigues Ferreira de Sousa; MOURA, Patrícia da Costa; PORFÍRIO, Patrícia de Almeida; FERNANDES, Pedro Davi de Leite Universidade do Porto; Faculdade de Engenharia:

Produção de iogurte. Outubro 2010. Disponível em

http://paginas.fe.up.pt/ projfeup/cd_2010_11/ files/QUI608_relatorio.pdf

HANSEN, C. H. R. Cultura liofilizada para iogurte, Rev. Food ingrediends. Editora fonte.Ed. Set/out 2002. Valinhos, SP.

LOMBRAÑA, J. I. E IZKARA, J. "Experimental estimation of effective tranposrts coefficients in freeze drying for simulation and optimization purposes", Drying Technology, 14(3), pp. 743-763, 1996.

ORDÓÑEZ, Juan A.; Tecnologia de Alimentos, Vol. 2 Alimentos de Origem Animal; trad. Fátima Murad.-Porto Alegre: Artmed, 2005.

PITOMBO, R. N. M. "Aliofilização como técnica de conservação de material de pesquisa", In: SBPC Ciência e Cultura, pp. 427-431, 1989
RATTI, C. "Hot air and freeze-drying of high-value foods: a review", Journal of Food Engineering, 49, pp. 311-319, 2001.

SENAR- Serviço Nacional de Aprendizagem Rural; Iogurte, bebidas lácteas e doce de leite: produção de derivados do leite--- 2.ed. Brasília: SENAR, 2010. ISBN 978-857664047-9.

TAMIME, A. Y.; DEETH, H. C. Yogurt: techonology and biochemestry. Journal of Food Protection, v. 43, n. 12, p. 939-977, 1980

\section{AGRADECIMENTOS}

Os autores agradecem o apoio financeiro na Coordenação de Pesquisa (COPES) da Universidade Federal de Sergipe. 